\title{
Photocatalytic Degradation of Antibiotics and Dyes in Wastewater by Hydrogenated Black Titanium Dioxide Nanoparticles Using Design of Experiment L9 Taguchi Orthogonal Array
}

\author{
Alma L. Valenzuela, Michael Green, and Xiaobo Chen* \\ Department of Chemistry, University of Missouri-Kansas City, MO 64110, United States \\ Email: chenxiaobo@umkc.edu (X. C.)
}

\begin{abstract}
Aqueous pollution from industrial dyes and antibiotics has brought up much threat to our daily healthy life. In the present work, hydrogenated black $\mathrm{TiO}_{2}$ nanoparticles $\left(\mathrm{H}-\mathrm{TiO}_{2}\right)$ are synthetized, their properties are studied, and their potentials in removing dyes (methylene blue, M.B.) and antibiotics such as tetracycline hydrochloride (TC) and ciprofloxacin (CIP) are explored with the support of statistical optimization. The operational controlled parameters such as catalyst amount $\left(\mathrm{g} \mathrm{L}^{-1}\right), \mathrm{pH}$ and irradiation time $(\mathrm{min})$ were optimized using Design of Experiment (DOE) L9 Taguchi Orthogonal Array. From Analysis of Variance (ANOVA) results, it can be seen that irradiation time is the most influencing parameter for \% MB color removal, \% Degradation of TC and $\mathrm{CIP}$, over catalyst amount and $\mathrm{pH}$. The optimal parameters found here are $0.50 \mathrm{~g} \mathrm{~L}^{-1}$ of hydrogenated $\mathrm{H}-\mathrm{TiO}_{2}-750$ as catalyst, $\mathrm{pH} 4$ for $\mathrm{MB}, \mathrm{pH} 11$ for $\mathrm{TC}$ and $\mathrm{pH} 2$ for CIP, respectively. In addition, an irradiation time of 30 min shows a maximum MB color removal of $95.05 \%$, TC $94.8 \%$ and CIP $92.25 \%$. Irradiation time is found to be the most influencing parameter $(71.08 \%$ for $\mathrm{MB}, 55.33 \%$ for TC and $52.77 \%$ for CIP) followed by catalyst amount $(28.82 \%$ for MB, $44.19 \%$ for TC and $41.5 \%$ for CIP) and in the end $\mathrm{pH}(0.09 \%$ for $\mathrm{MB}, 0.47 \%$ for TC and $5.72 \%$ for $\mathrm{CIP}$ ). With the use of hydrogenated $\mathrm{H}-\mathrm{TiO}_{2}-750$, the dye and antibiotics degradation reaches almost $40 \%$ more than using $\mathrm{TiO}_{2}$ pristine anatase.
\end{abstract}

Keywords dyes \& antibiotics, titanium (IV) oxide, statistical optimization, taguchi orthogonal array, black $\mathrm{TiO}_{2}$

\section{Introduction}

Wastewater from the use of dyes and pharmaceutical products such as antibiotics contaminate a substantial and important part of our sources of consumable water. The increasing use of antibiotics such as tetracycline hydrochloride (TC) and ciprofloxacin (CIP) (Table S1) to treat bacterial infections in people is leading us to increasingly pollute different environmental compartments such as drinking water. Thus, it is necessary to address the environmental problems that have arisen due to the indispensable use of antibiotics used for human health. ${ }^{[1]}$ On the other hand, the use of dyes by industries, such as dyestuffs, textile, paper and plastics, consume substantial volumes of water. As a result, they generate a considerable amount of colored wastewater. ${ }^{[2]}$ The water resulting from the dyeing industry in particular constitutes one of the most difficult wastewater to be treated, due to among other things to suspended solids, its high content of toxic substances, in addition to color, which is the first pollutant recognized by the human eye. Dyes can significantly affect photosynthetic activity in aquatic life because of the reduction of light penetration and can be toxic to aquatic life due to the presence of aromatics, metals, chlorides, etc., in them. ${ }^{[3]}$ Synthetic dyes such as Methylene Blue (MB) (Table S1) is part of a group of organic pollutants that are used extensively in textile (i.e., denim clothes). It is reported that there are over 100,000 commercially available dyes with a production of over $7 \times 10^{5}$ metric tons per year. ${ }^{[4]}$ Thus, researchers around the world are working for the remediation of contaminated water. As a result, there are different methods for cleaning wastewater by dyes and antibiotics, such is the case of biological treatments, ${ }^{[5]}$ adsorption, ${ }^{[6-8]}$ coagulation-flocculation, ${ }^{[9,10]}$ ozonation process, ${ }^{[11]}$ catalytic oxidation ${ }^{[12]}$ and electrochemical methods. ${ }^{[13]}$

In recent years, $\mathrm{TiO}_{2}$ photocatalysis has gained particular interest because of heterogeneous nature that offers the possibility of catalyst reuse. $\mathrm{TiO}_{2}$ is environmentally friendly, biocompatible, abundantly available, highly stable and low cost. ${ }^{[14-20]} \mathrm{TiO}_{2}$ has three polymorphs, rutile, anatase and brookite. Anatase is the most photoactive, which is improved by its high crystallinity and large surface area. ${ }^{[21-24]}$ Various methods have been developed for synthetizing nano-sized $\mathrm{TiO}_{2}$ nanoparticles, such as vapor synthesis, ${ }^{[25]}$ thermal decomposition process, ${ }^{[26-28]}$ chemical vapor deposition, ${ }^{[29]}$ flame synthesis, ${ }^{[30]}$ heat-threated flame-synthesized, ${ }^{[31]}$ solvothermal method, ${ }^{[32]}$ among others. We have recently developed hydrogenation as a new method for making $\mathrm{TiO}_{2}$ nanoparticles, which showed remarkably improved photocatalytic activity in hydrogen production from water and pollutant removal. ${ }^{[16]}$ Since that work, many methods and impressive work have been done to make black and colored $\mathrm{TiO}_{2}$ nanoparticles. For example, Mao et al. prepared blue $\mathrm{TiO}_{2}$ nanoparticles of high photocatalytic activity with hydrothermal and chemical reduction using $\mathrm{N}_{2} \mathrm{H}_{4}$. ${ }^{[33]}$ Huang et al. ${ }^{[3]}$ and Zhu et al. ${ }^{[35]}$ reported the synthesis of black $\mathrm{TiO}_{2}$ by $\mathrm{Al}$ reduction at high temperature. Wang et al. prepared black $\mathrm{TiO}_{2}$ nanoparticles in a thermal plasma furnace by hydrogen plasma at $500{ }^{\circ} \mathrm{C} .{ }^{[36]}$ Kang et al. synthesized reduced black $\mathrm{TiO}_{2}$ nanotubes by chemical reduction with $\mathrm{NaBH}_{4}{ }^{[37]} \mathrm{Xu}$ et al. prepared hydrogenated black $\mathrm{TiO}_{2}$ nanotubes by electrochemical reduction. ${ }^{[38]}$ Exciting photocatalytic activity has been reported on the black $\mathrm{TiO}_{2}$, especially when compared to the normal white $\mathrm{TiO}_{2}$.

In this work, we investigate the photocatalytic activity of hydrogenated black $\mathrm{TiO}_{2}$ nanoparticles on the removal of $\mathrm{MB}$ and antibiotics TC and CIP \% with the support of statistical 
optimization, namely, with Design of Experiment (DOE) L9 Taguchi Orthogonal Array.

\section{Materials and methods}

\section{Reagents and chemicals}

All the chemicals used here were of the highest purity grade: methylene blue chloride powder (Basic blue 9) from Fisher Chemical was used at $10 \mathrm{mg} \mathrm{L}^{-1}$, tetracycline hydrochloride powder $>98.0 \%$ from Tokyo Chemical Industry, Co. was used at $40 \mathrm{mg} \mathrm{L}^{-1}$, ciprofloxacin powder $98 \%$ from Alfa Aesar at 40 $\mathrm{mg} \mathrm{L}^{-1}$, titanium (IV) dioxide anatase $\geq 99.0 \%$ was purchased Sigma-Aldrich. In order to maintain an acidic medium (i.e., a pH of 2.0, 4.0 and 5.0) a solution of $0.010,0.00010$ and 0.000010 $\mathrm{M}$ of $\mathrm{HCl}$ (Fisher Chemical certified ACS plus) were used, respectively. In the case of the basic samples (i.e., $\mathrm{pH}$ of 9 and 11), solutions of 0.0010 and $0.000010 \mathrm{M} \mathrm{NaOH}$ (LabChem, ACS $97.0 \%$ ) were employed. Sodium Sulfate $\geq 99.0 \%$ was obtained from Sigma-Aldrich. In all experiments, deionized water from LabChem $100 \% \mathrm{pH} 7.0$ was used.

\section{Hydrogenated $\mathrm{TiO}_{2}$ black nanoparticles synthesis}

Commercial anatase $\mathrm{TiO}_{2}$ particles was obtained from Sigma-Aldrich and used without further purification. In a typical synthesis, $2.0 \mathrm{~g}$ of $\mathrm{TiO}_{2}$ raw anatase was grinded via mortar and pestle for around $15 \mathrm{~min}$ and then placed in a high-temperature tube furnace and treated at certain temperatures $(600,650,700$ and $750{ }^{\circ} \mathrm{C}$ ) and pressure (30 psi) under hydrogen atmosphere for $3 \mathrm{~h}$. The cooled sample was removed from the tube furnace to obtain the hydrogen treated $\mathrm{TiO}_{2}$ black nanoparticles, which was namely as $\mathrm{H}_{2}-\mathrm{TiO}_{2}-\mathrm{X}$, where $\mathrm{X}$ was the temperature.

\section{Materials characterization}

The synthesized $\mathrm{TiO}_{2}$ samples were characterized by several techniques. The ultraviolet-visible (UV-vis) spectra were measured using an Agilent Cary 60 spectrometer with a fiber optical reflectance unit. UV-vis diffusion reflectance spectra of the photocatalysts were collected using Cary 60 UV-vis Agilent Technologies spectrophotometer. $\mathrm{MgO}$ was used as reference sample, and its reflectance was assumed $100 \%$ throughout the spectrum. The X-ray diffraction (XRD) patterns were taken on a Rigaku Miniflex instrument with diffraction angle $2 \theta$ in between $20^{\circ}$ and $70^{\circ}$ using $\mathrm{Cu} \mathrm{Ka}$ as the X-ray source $(\lambda=1.54056 \AA)$. The transmission electron microscopy (TEM) analysis was taken on an FEI Tecnai F20 TEM machine with the electron accelerating voltage of $200 \mathrm{kV}$. A small amount of sample dispersed in water was dropped onto a thin holey carbon film and dried overnight before TEM measurement. The Brunauer-Emmett-Teller (BET) specific surface areas of raw $\mathrm{TiO}_{2}$ anatase and hydrogenated $\mathrm{TiO}_{2}$ black nanoparticles synthetized at different temperatures $\left(600,650,700\right.$ and $750{ }^{\circ} \mathrm{C}$, respectively) were performed by nitrogen sorption on a Micrometrics ASAP 2020 Surface Area and Porosity Analyzer. The pore size distribution (pore diameter and pore volume of the samples) was determined by the Barrett-Joyner-Halenda (BJH). For the ESR spectra active spectrum, MicroESR was run. In the case of photocurrent and impedance tests a potentiostat, BioLogic Science Instruments SP-150 was used. In addition, $\mathrm{pH}$ was monitored by $\mathrm{pH}$ meter Fisher Scientific Accumet ${ }^{\circledR} \mathrm{AE} 150$ and $\mathrm{a}$ light source (Newport power supply, $P=150 \mathrm{~W}$ ) was employed.

\section{Photoelectrochemical measurements}

Photocurrent intensity (PC) and electrochemical impedance spectroscopy (EIS) of the photocatalysts were carried out in a conventional three-electrode electrochemical cell with hydrogenated $\mathrm{H}_{2}-\mathrm{TiO}_{2}$ synthesized at different temperatures $(600$, 650,700 and $750{ }^{\circ} \mathrm{C}$, respectively) and pristine $\mathrm{TiO}_{2}$ anatase samples as working electrodes, a platinum wire as counter electrode and $\mathrm{Ag} / \mathrm{AgCl}$ as reference electrode. The electrolyte employed here was a solution of $\mathrm{Na}_{2} \mathrm{SO}_{4}, 0.5 \mathrm{M}$ and a source of visible light $(P=150 \mathrm{~W})$ was used. The working electrodes were prepared as follow: $32 \mathrm{mg}$ of hydrogenated $\mathrm{TiO}_{2}$ synthetized at different temperatures $\left(600,650,700\right.$ and $750{ }^{\circ} \mathrm{C}$, respectively) and pristine $\mathrm{TiO}_{2}$ anatase, $4 \mathrm{mg}$ of carbon black and $4 \mathrm{mg}$ of polyvinylidene fluoride (PVDF). All above materials quantities were grinded together via mortar and pestle until homogeneous (about $15 \mathrm{~min}$ ). After that, 4 drops of $\mathrm{N}$-methyl-2-pyrrolidone (NMP) were added to the mixture, and continued grinding for about $5 \mathrm{~min}$ more. Previously several strips of titanium screen mesh -2 mil $(1 \mathrm{~cm}$ width $\times 3 \mathrm{~cm}$ long) were washed and weighed in order to apply the resulting mixture on them. The mixture obtained above was deposited in the strips (about $1 \mathrm{~cm}^{2}$ each); after that, they were allowed to dry on a stove overnight. Once the electrodes were ready, they were weighed and measured in an electrochemical workstation.

\section{Photocatalytic evaluation}

During the photocatalytic degradation of $\mathrm{MB}, \mathrm{TC}$ and CIP, a beaker was used as a cell; $30 \mathrm{~mL}$ of $10 \mathrm{mg} \mathrm{L}^{-1} \mathrm{MB}, 40 \mathrm{mg} \mathrm{L}^{-1}$ of TC and $40 \mathrm{mg} \mathrm{L}^{-1}$ of CIP were deposited within it and irradiated by a source of visible light $(P=150 \mathrm{~W})$, respectively. Then, a sample of $3 \mathrm{~mL}$ was taken from the cell at certain conveniently time and analyzed. The absorbance of the sample was determined spectrophotometrically on an UV-vis spectrometer. The percentage of MB, TC and CIP dye degradation was calculated using the next expression:

$$
\% \mathrm{Deg}=\frac{A_{0}-A_{\mathrm{t}}}{A_{0}} \times 100
$$

where $A_{0}$ and $A_{t}$ are the absorbance at an initial time and a certain time $t$, respectively.

\section{Design of experiments and statistical evaluation}

Statistical Design of Experiments (DOE) is a structured and systematized method of experimentation, in which all factors are varied simultaneously over a set of experimental runs in order to determine the relationship between input factors affecting the output response during all the process. DOE technique can be useful for obtaining the relationship among variables and therefore save time by optimizing resources. ${ }^{[39]} \mathrm{DOE}$ was carried out using Minitab ${ }^{\circledR} 19$ as a statistical software.

To carry out this study, three factors have been considered such as $(\mathrm{A})$ catalyst amount $(\mathrm{CA})\left(\mathrm{g} \mathrm{L}^{-1}\right),(\mathrm{B}) \mathrm{pH}$, and (C) irradiation time (IT) (min) (Table 1).

Table 1 Factors and levels to be considered in DOE L9 Taguchi Orthogonal array

\begin{tabular}{cccc}
\hline Factors & Level 1 & Level 2 & Level 3 \\
\hline A & A1 & A2 & A3 \\
Catalyst Amount $\left(\mathrm{g} \mathrm{L}^{-1}\right)$ & 0.10 & 0.25 & 0.50 \\
\hline B & B1 & B2 & B3 \\
MB pH & 4 & 5 & 7 \\
CIP pH & 2 & 5 & 7 \\
TC pH & 7 & 9 & 11 \\
\hline C & C1 & C2 & C3 \\
Irradiation Time (min) & 10 & 20 & 30 \\
\hline
\end{tabular}

The DOE by complete factorial design of three factors and three levels $\left(3^{3}\right)$ results in 27 experiments, because this is the minimum number of executions required to analyze the factorial effect of the entire process. Although in practice, it turns out to 
Table 2 DOE L9 Taguchi Orthogonal array proposed for MB, TC and CIP degradation

\begin{tabular}{cccc}
\hline Exp. \# & Catalyst amount $/\left(\mathrm{g} \mathrm{L}^{-1}\right)$ & $\mathrm{pH}$ & Irradiation time/min \\
\hline 1 & $\mathrm{~A} 1$ & $\mathrm{~B} 1$ & $\mathrm{C} 1$ \\
2 & $\mathrm{~A} 1$ & $\mathrm{~B} 2$ & $\mathrm{C} 2$ \\
3 & $\mathrm{~A} 1$ & $\mathrm{~B} 3$ & $\mathrm{C} 3$ \\
4 & $\mathrm{~A} 2$ & $\mathrm{~B} 1$ & $\mathrm{C} 2$ \\
5 & $\mathrm{~A} 2$ & $\mathrm{~B} 2$ & $\mathrm{C} 3$ \\
6 & $\mathrm{~A} 2$ & $\mathrm{~B} 3$ & $\mathrm{C} 1$ \\
7 & $\mathrm{~A} 3$ & $\mathrm{~B} 1$ & $\mathrm{C} 3$ \\
8 & $\mathrm{~A} 3$ & $\mathrm{~B} 2$ & $\mathrm{C} 1$ \\
9 & $\mathrm{~A} 3$ & $\mathrm{~B} 3$ & $\mathrm{C} 2$ \\
\hline
\end{tabular}

be expensive and tedious because they must be done at least twice to ensure repeatability. Orthogonal array methods provide an alternative by reducing the entire factorial to a fractional one, therefore, reduce the minimum number of runs. With this array, the experiment can be carried out completely randomly (Table 2).

The response surface methodology (RSM) is a widely used mathematical and statistical method for modeling and analyzing a process, in which the response of interest is affected by various variables and the objective of this method is to optimize the response. The parameters that affect the process are called independent variables, while the responses are called dependent variables. ${ }^{[40,41]}$

The parameters analyzed were optimized using RSM, considering as a response variable \% color removal of $\mathrm{MB}, \%$ degradation of TC and \% degradation of CIP. In order to know the relationship between the controllable input parameters and the output response, the follow first order response surface model was used.

$$
Y=\beta_{0}+\beta_{1} X_{1}+\beta_{2} X_{2}+\beta_{3} X_{3}
$$

where $Y=$ predicted response (response function), $\beta_{0}=$ Intercept coefficient (offset), $\beta_{1}, \beta_{2}$, and $\beta_{3}=$ linear terms (first order) and $X_{1}, X_{2}$ and $X_{3}=$ Uncoded independent variables.

\section{Results and Discussion}

\section{Photocatalyst characterization}

The XRD patterns in Figure 1A with the well-defined diffraction peaks suggested that pristine and hydrogenated $\mathrm{TiO}_{2}$ black nanoparticles synthesized at different temperatures $(600,650$, 700 and $750^{\circ} \mathrm{C}$ ) had highly crystalline anatase phase. All peaks values matched well with anatase phase JCPDS card No. 21-1272 with the first peak at $2 \theta=24.8^{\circ}$ corresponding to the (101) plane, and other main peaks at $2 \theta=37.3^{\circ}, 47.6^{\circ}, 53.5^{\circ}$, 55.1 and $62.2^{\circ}$ corresponding to the crystal planes (004), (200), (105), (211) and (204), respectively. ${ }^{[14-19]}$ The TEM images in Figure $1 \mathrm{~B}$ showed that the pristine $\mathrm{TiO}_{2}$ nanoparticles had an average primary particle size of $15 \mathrm{~nm}$ in diameter (Figure $1 \mathrm{~B}-(1))$ and were highly crystallinized with well-defined lattice fringes and shape particle edges (Figure 1B-(2)), and the hydrogenated $\mathrm{TiO}_{2}$ nanoparticles showed a similar average particle size around $15 \mathrm{~nm}$ in diameter (Figure 1B-(3)), and had a well crystallized core surrounded by a layer of disordered structure due to the formation of structural defects (Figure $1 \mathrm{~B}-(4)) .^{[15,42,43]}$

It is well known that the photocatalytic activity will depends on how many photoexcited charges are created that is available for the photocatalysis process. Their numbers can be probed with the photocurrent measurement. Photocurrent density of pristine and hydrogenated $\mathrm{TiO}_{2}$ nanoparticles is shown in

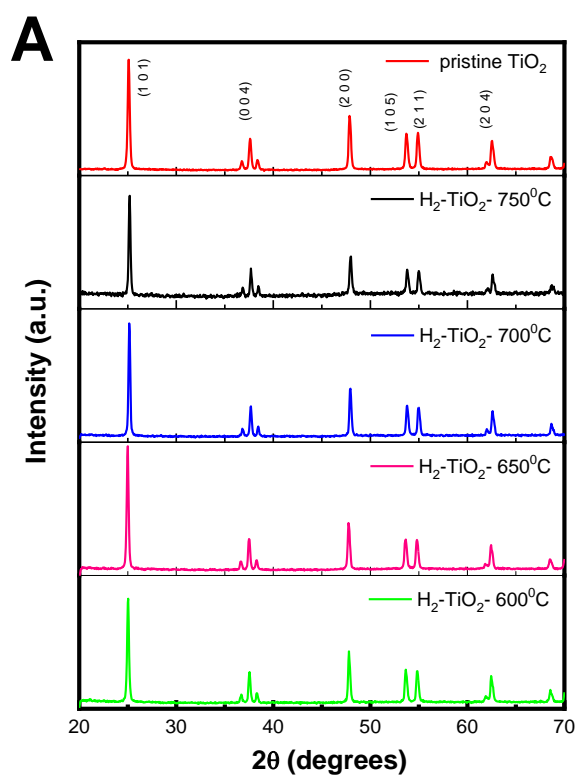

\section{B}
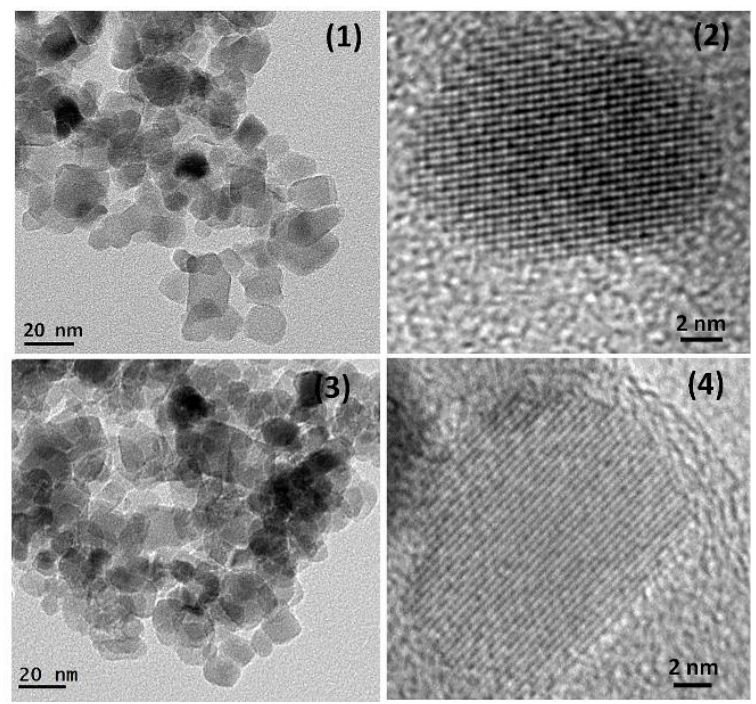

Figure 1 (A) XRD patterns of pristine and hydrogenated $\mathrm{TiO}_{2}$ nanoparticles. (B) TEM images of $\mathrm{TiO}_{2}$ nanoparticles. $(1,2)$ pristine $\mathrm{TiO}_{2},(3,4)$ hydrogenated $\mathrm{TiO}_{2}$ treated at $600{ }^{\circ} \mathrm{C}$.

Figure 2a. The measurements were taken using a voltage source at $0.4 \mathrm{~V}$ and measuring the response of each sample to the illumination generated from a Xe lamp $(150 \mathrm{~W})$ applied for $20 \mathrm{~s}$ and then turned off. The photocurrent was normalized with respect to the mass of the catalyst applied in the working electrodes. The intensity of the photocurrent density difference between light on and off or the net photocurrent density roughly reflects the amount of photoexcited charges that can be transported to the outside circuit. Normally, the more photoexcited charges are generated, the larger the intensity of the photocurrent density can be observed, assuming similar percentages of photoexcited charges are consumed or trapped within the photocatalysts. Apparently, more photoexciated charges that can be extracted are produced on the $\mathrm{TiO}_{2}$ nanoparticles hydrogenated at higher temperatures, as higher photocurrent density is observed. Figure 2B displayed the comparison of the net photocurrent density. It increased from 2.52 to $3.52,6.04$, 6.94 and $8.47 \mathrm{~mA} / \mathrm{cm}^{2} \mathrm{~g}$ from pristine anatase to hydrogenated 

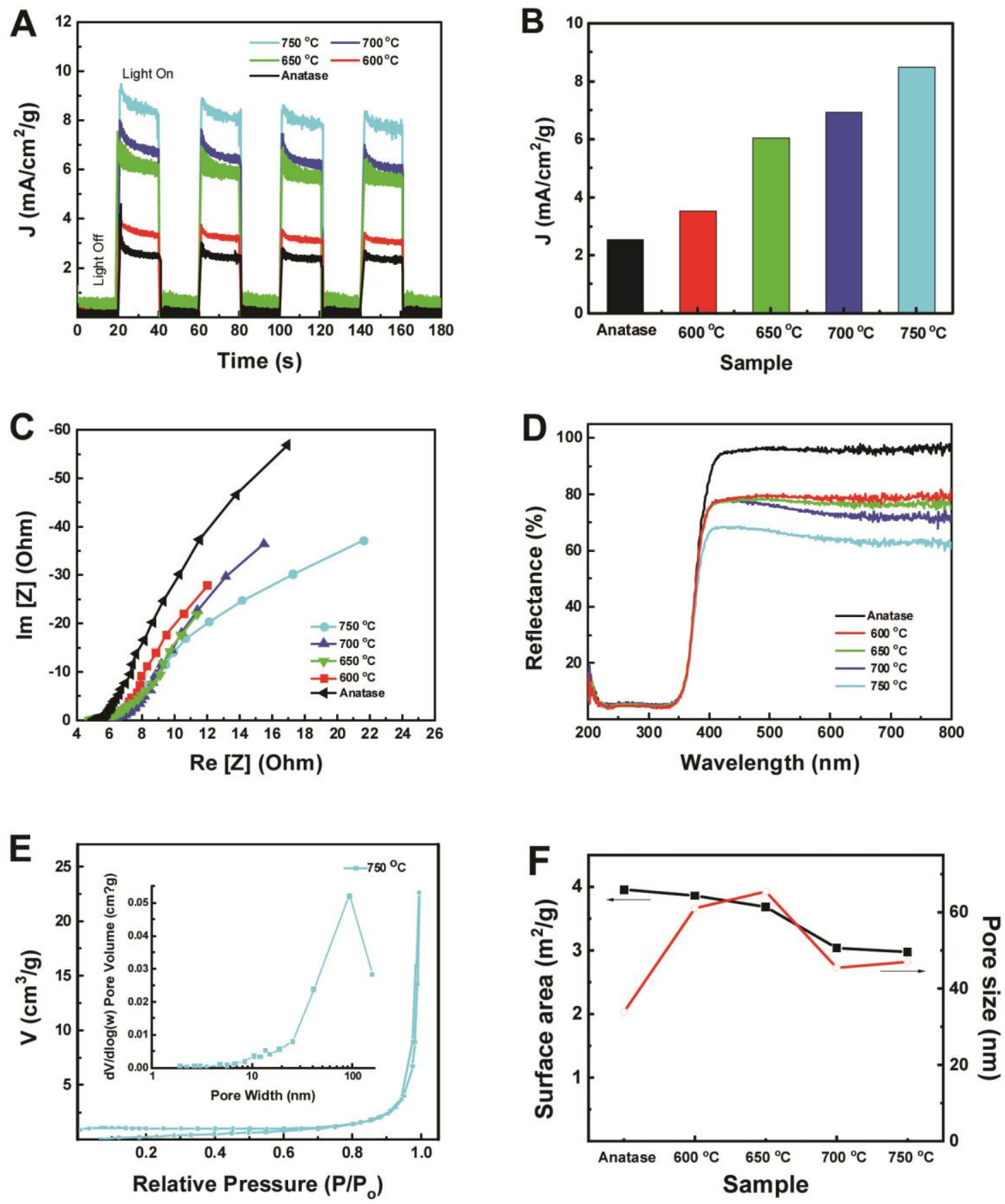

Figure 2 (A) Time-dependent photocurrent density (J), (B) Comparison of photocurrent density (J), (C) EIS Nyquist plots, (D) UV-vis reflectance spectra, (E) BET surface area and BJH pore size distribution curve, (F) Comparison of surface areas and pore size of pristine anatase $\mathrm{TiO}_{2}$ and hydrogenated $\mathrm{TiO}_{2}$ nanoparticles at various temperatures.

$\mathrm{TiO}_{2}$ at $600,650,700$ and $750{ }^{\circ} \mathrm{C}$, respectively. Compared with that of the pristine $\mathrm{TiO}_{2}$ nanoparticles, the intensity of the hydrogenated $\mathrm{TiO}_{2}$ nanoparticles at $750{ }^{\circ} \mathrm{C}$ increased $336 \%$. Obviously, hydrogenation considerably increased the photocurrent density of $\mathrm{TiO}_{2}$ nanoparticles.

Meanwhile, the photocatalytic activity also depends on how easy the charge transfer is on the surface of the photocatalyst. Such surface charge transfer resistance can be probed with EIS. Figure $2 \mathrm{C}$ displayed the EIS Nyquist plots. In the EIS plot, the diameter of the semicircle represents the charge transfer resistance. A smaller semicircle means a smaller charge separation resistance. Judged from the diameter of the semicircle, the surface charge transfer resistance seemed to decrease with the increase of the hydrogenation temperature. In other words, the surface charge transfer resistance decreases in the order of anatase $\mathrm{TiO}_{2}>600^{\circ} \mathrm{C}>650^{\circ} \mathrm{C}>700^{\circ} \mathrm{C}>750^{\circ} \mathrm{C}$. Therefore, hydrogenation reduces the surface charge transfer for photocatalysis.

The amount of photoexcited charges is directly related to the amount of light absorbed by the photocatalyst. Figure 2D 

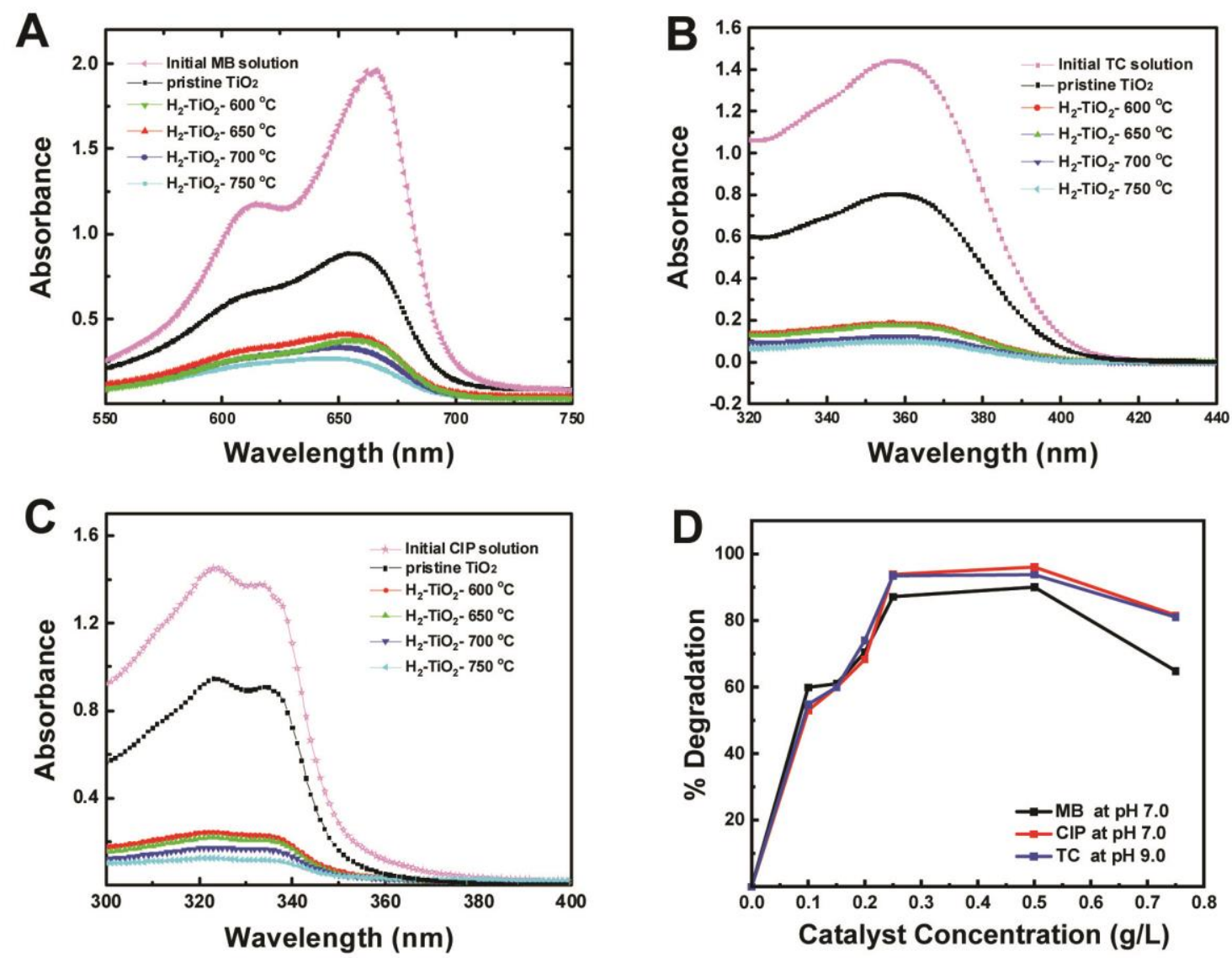

Figure 3 (A) MB, (B) TC and (C) CIP degradation with various catalysts $\left(0.25 \mathrm{~g} \mathrm{~L}^{-1}\right)$ after 30 min irradiation $\left(10 \mathrm{mg} \mathrm{L}^{-1} \mathrm{MB}(\mathrm{pH} 7.0)\right.$, $40 \mathrm{mg} \mathrm{L}^{-1}$ of TC $(\mathrm{pH} \mathrm{9.0)}$ and $\mathrm{CIP}(\mathrm{pH} 7.0))$. D) MB, TC and CIP degradation with various catalyst concentrations (irradiation time: 30 min, $10 \mathrm{mg} \mathrm{L}^{-1} \mathrm{MB}(\mathrm{pH} 7.0), 40 \mathrm{mg} \mathrm{L}^{-1}$ of $\mathrm{TC}(\mathrm{pH} \mathrm{9.0)}$ ) and $\mathrm{CIP}(\mathrm{pH} \mathrm{7.0)})$.

showed the diffuse reflectance spectra pristine and hydrogenated $\mathrm{TiO}_{2}$ nanoparticles. The bulk bandgaps of the pristine and hydrogenated $\mathrm{TiO}_{2}$ nanoparticles were similar, around $3.0 \mathrm{eV}$, estimated from the intersection (about $410 \mathrm{~nm}$ ) of the extensions of the sharp drop near $400 \mathrm{~nm}$ and of the flat reflection above $400 \mathrm{~nm}$. This suggested that they had similar bulk optical absorption, consistent with the same highly crystalline anatase phase observed from their XRD patterns. Meanwhile, hydrogenated $\mathrm{TiO}_{2}$ nanoparticles had less reflection in the visible-light region, above $400 \mathrm{~nm}$, compared to the pristine anatase $\mathrm{TiO}_{2}$ nanoparticles. The amount of non-reflected light increased in the order of anatase $(4.1 \%)<$ $600{ }^{\circ} \mathrm{C}(17.3 \%)<650{ }^{\circ} \mathrm{C}(19.6 \%)<700{ }^{\circ} \mathrm{C}(24.0 \%)<750{ }^{\circ} \mathrm{C}$ $(32.6 \%)$. This indicated that the amount of light absorbed likely increased with the hydrogenated temperature, assuming the amount of scattered light was similar. This increased light absorption in the visible-light region was attributed to the disordered layer or structures created in the hydrogenated $\mathrm{TiO}_{2}$ nanoparticles, as we reported previously and seen from the HRTEM images shown in Figure 1B-4.

The BET specific surface areas and pore size distribution were displayed in Figures $2 \mathrm{E}$ and $\mathrm{S} 1-\mathrm{S} 4$. The isotherms with a distinct hysteresis loops in relative pressure $\left(P / P_{0}\right)$ range of $0.0-1.0$ belong to type IV, indicating that a mesoporous structure. The changes of the BET surface area and pore size distribution with the hydrogenation temperature were displayed in Figure 2E. The BET surface area of the samples decreased with the increase of hydrogenation temperature. Specifically, the surface area decreased from 3.96 to $3.86,3.68,3.04$ and $2.97 \mathrm{~m}^{2} / \mathrm{g}$ from the pristine anatase $\mathrm{TiO}_{2}$ nanoparticles to $\mathrm{TiO}_{2}$ nanoparticles hydrogenated at $600,650,700$ and $750{ }^{\circ} \mathrm{C}$, respectively. This was probably due to the progressive aggregation of small crystallites into larger particles. Meanwhile, the main pore size increased after the hydrogenation treatment. Specifically, the centered pore size increased from $33.9 \mathrm{~nm}$ to $61.1,65.5,45.5$ and $47.0 \mathrm{~nm}$ from the pristine anatase $\mathrm{TiO}_{2}$ nanoparticles to $\mathrm{TiO}_{2}$ nanoparticles hydrogenated at 600,650 , 700 and $750{ }^{\circ} \mathrm{C}$, respectively.

\section{DOE preliminary experiments}

Preliminary assessments were carried out by one factor at a time approach in order to know the ranges of the main three parameters; such as catalyst amount $\left(\mathrm{g} \mathrm{L}^{-1}\right)$ of dye and antibiotics, $\mathrm{pH}$ and irradiation time (min) for using later in the DOE Taguchi orthogonal array.

In the case of photocatalyst type, hydrogenated $\mathrm{TiO}_{2}$ synthesized at different temperatures $\left(600,650,700\right.$ and $\left.750{ }^{\circ} \mathrm{C}\right)$ were used. During photocatalytic degradation, each experiment was repeated by triplicate under the same conditions in order to ensure the repeatability. Figures $3 \mathrm{~A}-3 \mathrm{C}$ showed the degradation of MB, TC and CIP with various catalysts $\left(0.25 \mathrm{~g} \mathrm{~L}^{-1}\right)$ after 30 min irradiation, respectively. Clearly, the amounts of MB, TC and CIP degraded within $30 \mathrm{~min}$ roughly followed the same order: $\mathrm{TiO}_{2}$ nanoparticles hydrogenated at higher temperature displayed larger degradation and $\mathrm{TiO}_{2}$ hydrogenated at $750{ }^{\circ} \mathrm{C}$ showed the largest degradation, all much better than the pris- 
tine $\mathrm{TiO}_{2}$ nanoparticles.

Photocatalytic degradation is also affected by the concentration of photocatalytic used during the experiment. Figure 3D showed the results of using $\mathrm{H}-\mathrm{TiO}_{2}-750$ as the catalyst with various concentration from 0.10 to $0.75 \mathrm{~g} \mathrm{~L}^{-1}$. The increase in catalyst quantity enhances the number of active sites, increasing hydroxyl radicals production and as a result of this, it improves the degradation of dye and antibiotics. This behavior is consequential from 0.10 to $0.25 \mathrm{~g} / \mathrm{L}$. Further increase from 0.25 to $0.50 \mathrm{~g} / \mathrm{L}$ only slightly increased the amount of degradation. When the concentration was larger than $0.50 \mathrm{~g} / \mathrm{L}$, the degradation decreased instead. This can be attributed to the fact that the solution becomes cloudy and hence does not allow the light to pass through, limiting the production of radicals that are responsible for the photocatalytic reaction with contaminants and decreasing the photocatalytic action.

The effect of $\mathrm{pH}$ is one of the most important factors to consider for the photocatalytic degradation. To investigate such effect, preliminary experiments were carried out at different $\mathrm{pH}$ values (from 2.0 to 11.0) using hydrogenated $\mathrm{TiO}_{2}$ synthesized at $750{ }^{\circ} \mathrm{C}$ as catalyst, with a catalyst amount of $0.25 \mathrm{~g} \mathrm{~L}^{-1}$ and an irradiation time of $30 \mathrm{~min}$. Experiments were performed with irradiation axially to the sample using a stirrer magnetic in order to maintain samples homogeneously, all experiments were carried out at room temperature $\left(\approx 23^{\circ} \mathrm{C}\right)$. The results can be seen in Figure 4 . The best efficiency found for a) MB degradation is in the $\mathrm{pH}$ acid to neutral (range between 4.0 and 7.0, Figure 4A). For TC degradation the better efficiency was observed in alkaline conditions ( $\mathrm{pH}$ from 9.0 to 11.0) as seen in Figure 4B. Finally, the best results for CIP degradation were found from acid conditions to neutral ( $\mathrm{pH}$ from 2.0 to 7.0), as displayed in Figure 4C.

In order to investigate the reaction kinetics of dye and antibiotics photodegradation, the pseudo-first order model was applied to simulate experiment date using equation (4):

$$
k=\frac{c_{0}}{c_{t}}
$$

where $C_{0}$ and $C_{t}$ are the concentrations of the contaminants at time 0 and $t$, respectively, and $k$ is the pseudo-first order rate constant. Figure $5 \mathrm{~A}$ shows that the apparent rate constant for MB using a concentration of $0.10 \mathrm{~g} \mathrm{~L}^{-1}$ of catalyst is 0.07179 $\mathrm{min}^{-1}$, for $0.25 \mathrm{~g} \mathrm{~L}^{-1}$ of catalyst $k$ value is $0.07312 \mathrm{~min}^{-1}$ and at last for $0.50 \mathrm{~g}^{-1}$ of catalyst used, $k$ value is $0.08095 \mathrm{~min}^{-1}$. The $k$ value is higher for catalyst amount of $0.50 \mathrm{~g} \mathrm{~L}^{-1}$, about 1.127 times more than $0.10 \mathrm{~g} \mathrm{~L}^{-1}$ and 1.107 times more than $0.25 \mathrm{~g}$ $\mathrm{L}^{-1}$, respectively. From Figure $5 \mathrm{~B}$, it can be seen that the apparent rate constant for TC using a concentration of $0.10 \mathrm{~g} \mathrm{~L}^{-1}$ of catalyst is $0.07018 \mathrm{~min}^{-1}$, for $0.25 \mathrm{~g} \mathrm{~L}^{-1}$ of catalyst $k$ value is $0.07020 \mathrm{~min}^{-1}$ and at last for $0.50 \mathrm{~g}^{-1}$ of catalyst used, $k$ value is $0.07720 \mathrm{~min}^{-1}$. Using $0.50 \mathrm{~g} \mathrm{~L}^{-1}$ as catalyst amount, the apparent rate constant reaches 1.1 times than $0.10 \mathrm{~g} \mathrm{~L}^{-1}$ and 1.099 times more than $0.25 \mathrm{~g} \mathrm{~L}^{-1}$ severally. Figure $\mathrm{S} 5$ showed that the apparent rate constant for CIP using a concentration of $0.10 \mathrm{~g} \mathrm{~L}^{-1}$ of catalyst is $0.06963 \mathrm{~min}^{-1}$, for $0.25 \mathrm{~g} \mathrm{~L}^{-1}$ of catalyst $k$ value is $0.07154 \mathrm{~min}^{-1}$ and at last for $0.50 \mathrm{~g}^{-1}$ of catalyst used, $k$ value is $0.07506 \mathrm{~min}^{-1}$. It is clearly that the again $k$ apparent rate constant value is higher for catalyst amount of $0.50 \mathrm{~g} \mathrm{~L}^{-1}$ above the other values, about 1.078 times more than $0.10 \mathrm{~g} \mathrm{~L}^{-1}$ and 1.049 more than $0.25 \mathrm{~g} \mathrm{~L}^{-1}$.

\section{Statistical analysis}

With the above preliminary results, it was decided to make a complete study with the help of statistical optimization, varying three factors such as catalyst amount $(0.10,0.25$ and $0.50 \mathrm{~g}$ $\left.\mathrm{L}^{-1}\right), \mathrm{pH}$ (depending on the case of the pollutant) and irradiation time $(10,20$ and $30 \mathrm{~min})$ using hydrogenated $\mathrm{H}_{2}-\mathrm{TiO}_{2}-750^{\circ} \mathrm{C}$ as
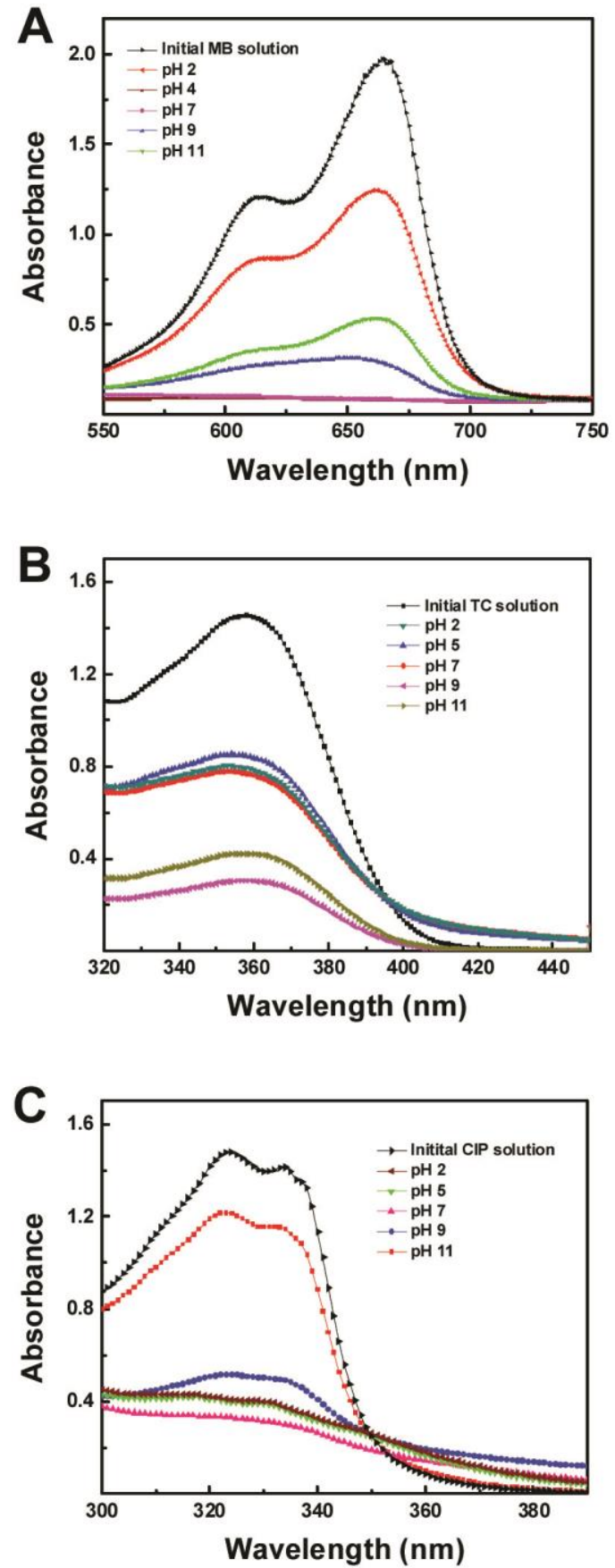

Figure 4 Degradation of (A) MB, (B) TC and (C) CIP after 30 min irradiation using $\mathrm{H}_{2}-\mathrm{TiO}_{2}-750(0.25 \mathrm{~g} / \mathrm{L})$ at various $\mathrm{pH}$ values (10 mg L-1 MB (pH 7.0), $40 \mathrm{mg} \mathrm{L}^{-1}$ of TC (pH 9.0) and CIP $(\mathrm{pH} 7.0))$.

catalyst. A L9 Taguchi Orthogonal array was implemented (Table 2).

Taguchi orthogonal arrays are balanced to ensure that all levels of all factors are considered equally. For this reason, the factors can be evaluated independently of each other despite the fractionally of the design. From Minitab ${ }^{\circledR} 19$ a L9 Taguchi array was obtained as can be seen in Table 2; the number of experiments was reduced from 27 to only 9 . In order to ensure repeatability, the experiments were performed in triplicate. The results obtained by implementing DOE values from Table 2 are displayed In Figure 6. Figure 6A shows the degradation of MB: the best parameters for almost $100 \%$ of degradation are 

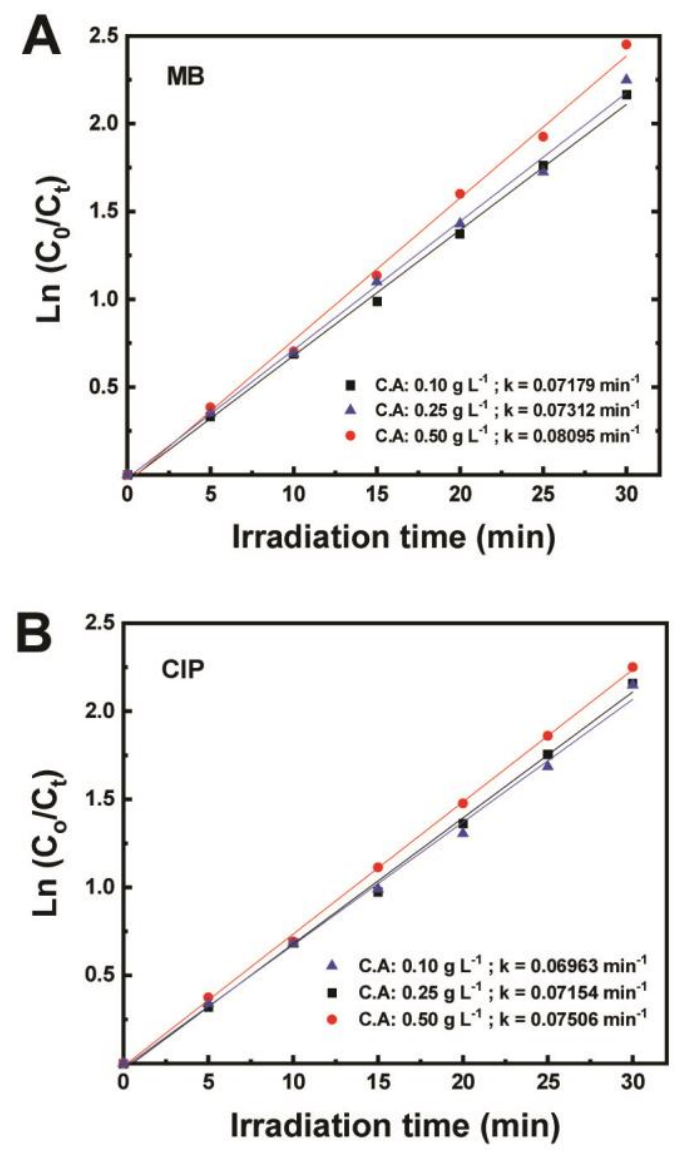

Figure 5 The pseudo-first order rate constants for (A) MB and (B) CIP photodegradation with various concentrations of catalyst $\mathrm{H}_{2}-\mathrm{TiO}_{2}-750$.

catalyst concentration $0.50 \mathrm{~g} \mathrm{~L}^{-1}, \mathrm{pH} 4.0$ and 30 min of irradiation. Figure $6 \mathrm{~B}$ shows the best parameters of TC degradation of about $95 \%$ are: catalyst concentration of $0.50 \mathrm{~g} \mathrm{~L}^{-1}, \mathrm{pH} 7.0$ and $30 \mathrm{~min}$ of irradiation. Figure $6 \mathrm{C}$ displayed that the best condition on degradation of CIP with almost $95 \%$ are catalyst concentration of $50 \mathrm{~g} \mathrm{~L}^{-1}, \mathrm{pH} 2.0$ and 30 min of irradiation.

Analysis of Variance (ANOVA) was used to investigate the influence of analyzed parameters such as catalyst amount, $\mathrm{pH}$ and irradiation time on the response variable MB, TC and CIP Degradation. The strategy of pooled sum of errors was conducted and the results of ANOVA for \% MB color removal and antibiotics degradation response are shown in Table S2. From the ANOVA of experimental results, the MB degradation was influenced by irradiation time $(71.08 \%)$ followed by catalyst concentration (28.83\%) and finally $\mathrm{pH}(0.09 \%)$. The TC degradation was influenced by irradiation time (56.45\%) followed by catalyst concentration (43.03\%) and $\mathrm{pH}(0.24 \%)$. The CIP degradation was influenced by irradiation time $(52.77 \%)$ followed by catalyst concentration $(41.5 \%)$ and $\mathrm{pH}$ (5.72\%).

The RSM method was used to optimize the response variable (\% Deg) influenced by different controlled parameters such as catalyst concentration (C.A.), $\mathrm{pH}$ and irradiation time (I.T.). The relationship between input and output parameters was obtained by:

$\%$ MB Deg $=-7.721+72.441$ C.A. $-0.538 \mathrm{pH}+2.2987$ I.T (5)

$\%$ TC Deg $=-13.86+87.85$ C.A $+0.9210 \mathrm{pH}+1.9863 \mathrm{I} . \mathrm{T}$

$\%$ CIP Deg $=6.290+75.890$ C.A. $-2.263 \mathrm{pH}+1.7291 \mathrm{I} . \mathrm{T}$
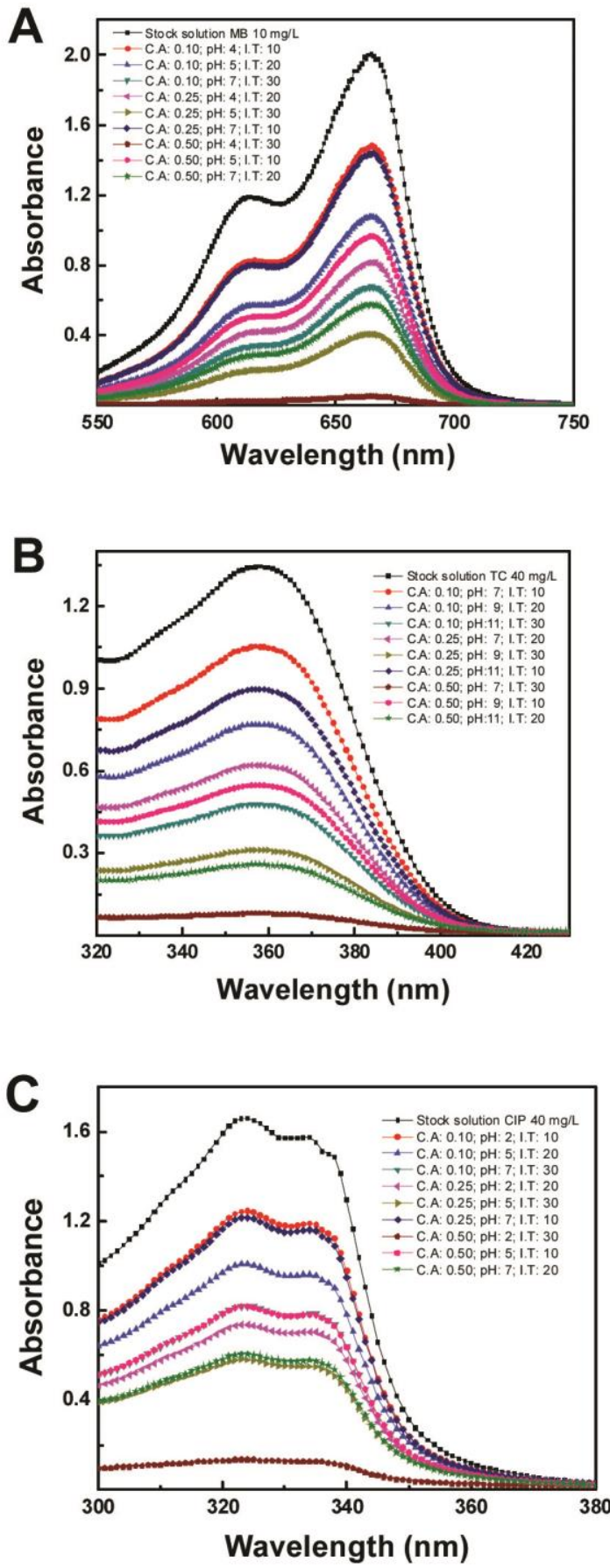

Figure 6 (A) MB, (B) TC and (C) CIP degradation with $\mathrm{H}_{-} \mathrm{TiO}_{2-}$ 750 using an array of L9 Taguchi Orthogonal.

The predicted values of \% deg were obtained by substituting the values of the parameters considered into Eqs. (5), (6) and (7). $R^{2}$ adjusted was found for this model (L9 Taguchi Orthogonal array). Obtained (real) and predicted values (calculated) are appreciated in Table S3.

Figure 7 shows the response surface for optimization parameters. The optimized values obtained here are: (A) For MB, catalyst concentration $0.50 \mathrm{~g} \mathrm{~L}^{-1}, \mathrm{pH} 4.0$ and 30 min irradiation time, and with the maximum percentage of $\mathrm{MB}$ degradation of $95.30 \%$. (B) For TC, catalyst concentration $0.50 \mathrm{~g} \mathrm{~L}^{-1}, \mathrm{pH} 11.0$ and irradiation time $30 \mathrm{~min}$ and with the maximum percentage 
A

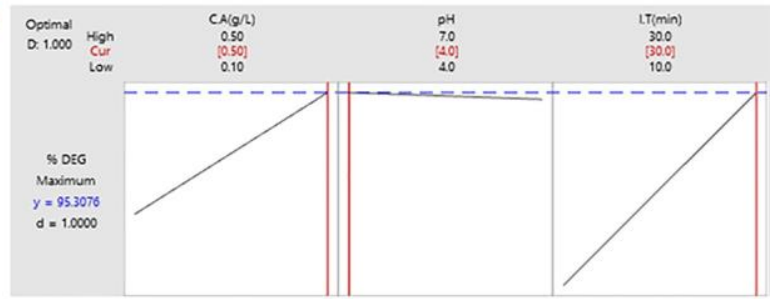

B

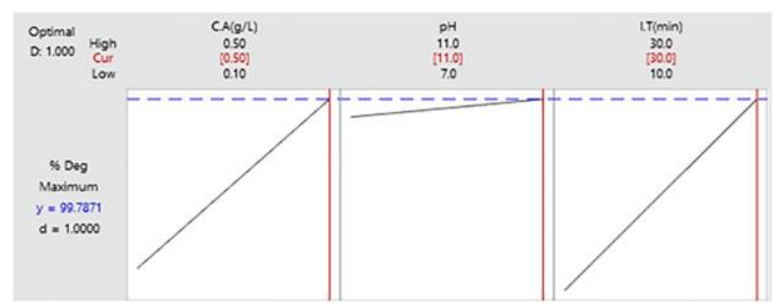

C

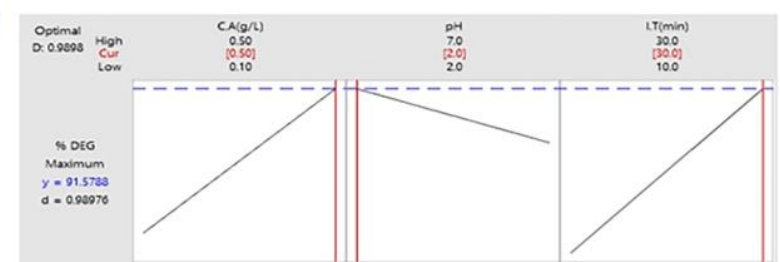

Figure 7 Response surface optimization parameters for $(A)$ $\mathrm{MB},(\mathrm{B}) \mathrm{TC}$ and $(\mathrm{C}) \mathrm{CIP}$.

of TC degradation of $99.78 \%$. (C) For CIP, catalyst concentration $0.50 \mathrm{~g} \mathrm{~L}^{-1}, \mathrm{pH} 2.0$ and irradiation time $30 \mathrm{~min}$ and the maximum percentage degradation of $91.57 \%$ by keeping these parameters value.

\section{Conclusions}

The photocatalytic application of hydrogenated $\mathrm{TiO}_{2}$ nanoparticles successfully carried out in the photocatalytic degradation of MB, TC and CIP. Several characterization techniques were used in order to know the catalyst's properties and photocatalytic performance. Each catalyst was subjected to the same tests and under the same circumstances by triplicate, in order to ensure repeatability. Hydrogenated $\mathrm{TiO}_{2}$ nanoparticles showed much better performance than pristine $\mathrm{TiO}_{2}$ nanoparticles, benefiting from the better photoexcited charge generation and separation that are needed for the photocatalysis. The $\mathrm{H}_{2}-\mathrm{TiO}_{2}-750$ showed the highest rate of photocatalytic power. Therefore, it was used for a more in-depth study with the support of statistical optimization. Degradation of MB, TC and CIP was implemented with the support of statistical optimization. A DOE Taguchi Orthogonal Array was performed in order to know the best factors influencing in the entire process. From ANOVA results, it can be seen that irradiation time is the most influencing parameter for the MB, TC and CIP degradation, over catalyst concentration and $\mathrm{pH}$.

\section{Acknowledgement}

A. V. appreciates the support from EPE-2019-1 CONACyT for the grant 2019-000029-01EXTV-00003 awarded for postdoctoral stay at the University of Missouri-Kansas City. X. C. acknowledges the support from the School of Biological and Chemical Sciences, University of Missouri-Kansas City.

\section{Supporting Information}

Supporting information for this article is available on the WWW under www.genchemistry.org/EN/10.21127/yaoyigc202
10006.

\section{Conflict of Interest}

The authors declare no conflict of interest.

Copyright (c) 2021 Alma L. Valenzuela, Michael Green, and Xiaobo Chen. This article is an open access article distributed under the terms and conditions of the Creative Commons Attribution (CC BY) license (http://creativecommons.org/licenses/by/4.0/). The use, distribution or reproduction in other forums is permitted, provided the original author(s) or licensor are credited and that the original publication in this journal is cited, in accordance with accepted academic practice. No use, distribution or reproduction is permitted which does not comply with these terms.

\section{References}

[1] Yuan, X.; Shen, D.; Zhang, Q.; Zou, H.; Liu, Z.; Peng, F. Z-Scheme $\mathrm{Bi}_{2} \mathrm{WO}_{6} / \mathrm{CuBi}_{2} \mathrm{O}_{4}$ Heterojunction Mediated by Interfacial Electric Field for Efficient Visible-Light Photocatalytic Degradation of Tetracycline. Chem. Eng. J. 2019, 369, 292-301.

[2] Crini, G. Non-Conventional Low-Cost Adsorbents for Dye Removal: A Review. Bioresour. Technol. 2006, 97, 1061-1085.

[3] Robinson, T.; McMullan, G.; Marchant, R.; Nigam, P. Remediation of Dyes in Textile Effluent: A Critical Review on Current Treatment Technologies with a Proposed Alternative. Bioresource Technol. 2001, 77, 247-255.

[4] Aksu, Z. Application of Biosorption for the Removal of Organic Pollutants: A Review. Process Biochem. 2005, 40, 997-1026.

[5] Kornaros, M.; Lyberatos, G. Biological Treatment of Wastewaters from a Dye Manufacturing Company using a Trickling Filter. J. Hazard Mater. 2006, 136, 95-102.

[6] Bentahar, S.; Dbik, A.; El Khomri, M.; El Messaoudi, N.; Lacherai, A. Adsorption of Methylene Blue, Crystal Violet and Congo Red from Binary and Ternary Systems with Natural Clay: Kinetic, Isotherm, and Thermodynamic. J. Environ. Chem. Eng. 2017, 5, 5921-5932.

[7] Chatterjee, S.; Lee, M. W.; Woo, S. H. Adsorption of Congo Red by Chitosan Hydrogel Beads Impregnated with Carbon Nanotubes. Bioresour. Technol. 2010, 101, 1800-1806.

[8] Crini, G.; Badot, P. M. Application of Chitosan, a Natural Aminopolysaccharide, for Dye Removal from Aqueous Solutions by Adsorption Processes Using Batch Studies: A Review of Recent Literature. Prog. Polym. Sci. 2008, 33, 399-447.

[9] Zharim, A. Y.; Hilal, H. Treatment of Highly Concentrated Dye Solution by Coagulation/Flocculation-Sand Filtration and Nanofiltration. Water Resour. Ind. 2013, 3, 23-34.

[10] Khayet, M.; Zahrim, A. Y.; Hilal, N. Modelling and Optimization of Coagulation of Highly Concentrated Industrial Grade Leather Dye by Response Surface Methodology. Chem. Eng. J. 2011, 167, $77-83$

[11] Zhang, X. B.; Dong, W. Y.; Yang, W. Decolorization Eficiency and Kinetics of Typical Reactive Azo Dye RR2 in the Homogeneous Fe (II) Catalized Ozonation Process. Chem. Eng. J. 2013, 233, 14-23.

[12] Pak, D.; Chang, W. Decolorizing Dye Wastewater with Low Temperature Catalytic Oxidation. Water Sci. Technol. 1999, 40, 115-121.

[13] Martinez-Huitle, C. A.; Brillas, E. Decontamination of Wastewaters Containing Synthetic Organic Dyes by Electrochemical Methods. A general review. Appl. Catal. B: Environ. 2009, 87, 105-145.

[14] Chen, X.; Mao, S. S. Titanium Dioxide Nanomaterials: Synthesis, Properties, Modifications, and Applications. Chem. Rev. 2007, 107, 2891-2959.

[15] Chen, X. Titanium Dioxide Nanomaterials and Their Energy Applications. Chin. J. Catal. 2009, 30, 839-851.

[16] Chen, X.; Liu, L.; Yu, P. Y.; Mao, S. S. Increasing Solar Absorption for Photocatalysis with Black Hydrogenated Titanium Dioxide Nanocrystals. Science 2011, 331, 746-750. 
[17] Liu, Y.; Li, Z.; Green, M.; Just, M.; Li, Y.; Chen, X. Titanium Dioxide Nanomaterials for Photocatalysis. J. Phys. D 2017, 50, 193003/1-15.

[18] Li, X.; Xia, T.; Xu, C.; Murowchick, J.; Chen, X. Synthesis and Photoactivity of Nanostructured $\mathrm{CdS}-\mathrm{TiO}_{2}$ Composite Catalysts. Catal. Today 2014, 225, 64-73.

[19] Xia, T.; Zhang, Y.; Murowchick, J.; Chen, X. Vacuum-Treated Titanium Dioxide Nanocrystals: Optical Properties, Surface Disorder, Oxygen Vacancy, and Photocatalytic Activities. Catal. Today 2014, 225, 2-9.

[20] Byrne, C.; Subramanian, G.; Pillai, S. C. Recent Advances in Photocatalysis for Environmental Applications. J. Environ. Chem. Eng. 2018, 6, 3531-3555.

[21] Vinodkumar, F.; Di Valentin, C.; Schneider, J.; Banhnemann, D.; Pillai, S. C. Visible-Light Activation of $\mathrm{TiO}_{2}$ Photocatalysts: Advances in Theory and Experiments. J. Photochem. Photobiol. C 2015, 25, 1-29.

[22] Inagaky, M.; Nakazawa, Y.; Hirano, M.; Kobayashi, Y.; Toyoda, M. Preparation of Stable Anatase-Type $\mathrm{TiO}_{2}$ and its Photocatalytic Performance. Int. J. Inorg. Mater. 2001, 3, 809-811.

[23] Moon, J.; Takagi, H.; Fujishiro, Y.; Awano, M. Preparation and Characterization of the Sb-doped $\mathrm{TiO}_{2}$ Photocatalysts. J. Mater. Sci. 2001, 36, 949-955.

[24] Ovenstone, J. Preparation of Novel Titania Photocatalysts with High Activity. J. Mater. Sci. 2001, 36, 1325-1329.

[25] Akhtar, M. K. Xiong, Y. Pratsinis, S. E. Vapor Synthesis of Titania Powder by Titanium Tetrachloride Oxidation. Am. Inst. Chem. Eng. J. 1991, 37, 1561-1570.

[26] Chin, S.; Jurng, J.; Lee, J. H.; Moon, S. J. Catalytic Conversion of 1,2-Dichlorobenzene Using $\mathrm{V}_{2} \mathrm{O}_{5} / \mathrm{TiO}_{2}$ Catalyst by Thermal Decomposition Process Chemosphere 2009, 75, 1206-1209.

[27] Payakgul, W.; Mekasuwandumrong, O.; Pavarajarn, V.; Praserthdam, P. Effects of Reaction Medium on the Synthesis of $\mathrm{TiO}_{2}$ Nanocrystals by Thermal Decomposition of Titanium (IV) n-Butoxide. Ceram. Int. 2005, 31, 391-397.

[28] Okuyama, K.; Jeung, J. T.; Kousaka, Y.; Nguyen, H. V.; Wu, J. J.; Flagan, R. C. Experimental Control of Ultrafine $\mathrm{TiO}_{2}$ Particle Generation from Thermal Decomposition of Titanium Tetraisopropoxide Vapor. Chem. Eng. Sci. 1989, 44, 1369-1375.

[29] Kuo, C. S.; Tseng, Y. H.; Huang, C. H.; Li, Y. Y. Carbon-Containing Nano-Titania Prepared by Chemical Vapor Deposition and its Visible-Light-Responsive Photocatalytic Activity. J. Mol. Catal. 2007, 270, 93-100.

[30] Akurati, K. K.; Vital, A.; Fortunato, G.; Hany, R.; Nueesch, F.; Graule, T. Flame Synthesis of $\mathrm{TiO}_{2}$ Nanoparticles with High Photocatalytic Activity. Solid State Sci. 2007, 9, 247-257.

[31] Lee, G. W.; Choi, S. C. Thermal Stability of Heat-Treated FlameSynthesized Anatase $\mathrm{TiO}_{2}$ Nanoparticles. J. Mater. Sci. 2008, 43, 715-720.

[32] Supphasrirongjaroen, P.; Praserthdam, P.; Panpranot, J.;
Na-Ranong, D.; Mekasuwandumrong, O. Effect of Quenching Medium on Photocatalytic Activity of $\mathrm{Nano}-\mathrm{TiO}_{2}$ Prepared by Solvothermal Method. Chem. Eng. J. 2008, 138, 622-627.

[33] Mao, C.; Zuo, F.; Hou, Y.; Bu, X.; Feng, P. In Situ Preparation of a $\mathrm{Ti}^{3+}$ Self-Doped $\mathrm{TiO}_{2}$ Film with Enhanced Activity as Photoanode by $\mathrm{N}_{2} \mathrm{H}_{4}$ Reduction. Angew. Chem. Int. Ed. 2014, 26, 10653-10657.

[34] Cui, H.; Zhao, W.; Yang, C.; Yin, H.; Lin, T.; Shan, Y.; Xie, Y.; Gua, H.; Huang, F. Black $\mathrm{TiO}_{2}$ Nanotube Arrays for High-Efficiency Photoelectrochemical Water-Splitting. J. Mater. Chem. A 2014, 2, 8612-8616.

[35] Song, H.; Li, C.; Lou, Z.; Ye, Z.; Zhu, L. Effective Formation of Oxygen Vacancies in Black $\mathrm{TiO}_{2}$ Nanostructures with Efficient Solar-Driven Water Splitting. ACS Sustain. Chem. Eng. 2017, 5 8982-8987.

[36] Wang, Z.; Yang, C.; Lin, T.; Yin, H.; Chen, P.; Wan, D.; Xu, F.; Huang, F.; Lin, J.; Xie, X.; Jiang, M. H-doped Black Titania with Very High Solar Absorption and Excellent Photocatalysis Enhanced by Localized Surface Plasmon Resonance. Adv. Funct. Mater. 2013, 23, 5444-5450.

[37] Kang, Q.; Cao, J.; Zhang, Y.; Liu, L.; Xu, H.; Ye, J. Reduced $\mathrm{TiO}_{2}$ Nanotube Arrays for Photoelectrochemical Water Splitting. J. Mater. Chem. A 2013, 1, 5766-5744.

[38] Xu, C.; Song, Y.; Lu, L.; Cheng, C.; Liu, D.; Fang, X.; Chen, X.; Zhu, X.; Li, D. Electrochemically Hydrogenated $\mathrm{TiO}_{2}$ Nanotubes with Improved Photoelectrochemical Water Splitting Performance. Nanoscale Res. Lett. 2013, 8, 391.

[39] Ghajar, S.; Sohrabi, M.R. Taguchi Experimental Design Used for Nano Photo Catalytic Degradation of the Pharmaceutical Agent Aspirin. J. Chem. Pharm. Res. 2012, 4, 814-821.

[40] Khayet, M.; Zahrim, A. Y.; Hilal, N. Modelling and Optimization of Coagulation of Highly Concentrated Industrial Grade Leather Dye by Response Surface Methodology. Chem. Eng. J. 2011, 167, 77-83.

[41] Bezerra, M. A.; Santelli, R. E.; Oliveira, E. P.; Silveira, V. L.; Escaleira, L. A. Response Surface Methodology (RSM) as a Tool for Optimization in Analytical Chemistry. Talanta 2008, 76, 965-977.

[42] Chen, X.; Liu, L.; Liu, Z.; Marcus, M. A.; Wang, W.-C.; Oyler, N. A.; Grass, M. E.; Mao, B.; Glans, P.-A.; Yu, P. Y.; Guo, J.; Mao, S. S. Properties of Disorder-Engineered Black Titanium Dioxide Nanoparticles through Hydrogenation. Sci. Rep. 2013, 3, 1510.

[43] Xia, T.; Wallenmeyer, P.; Anderson, A.; Murowchick, J.; Liu, L.; Chen, X. Hydrogenated Black ZnO Nanoparticles with Enhanced Photocatalytic Performance. RSC Adv. 2014, 4, 41654-41658.

Received May 24, 2021

Accepted June 22, 2021 